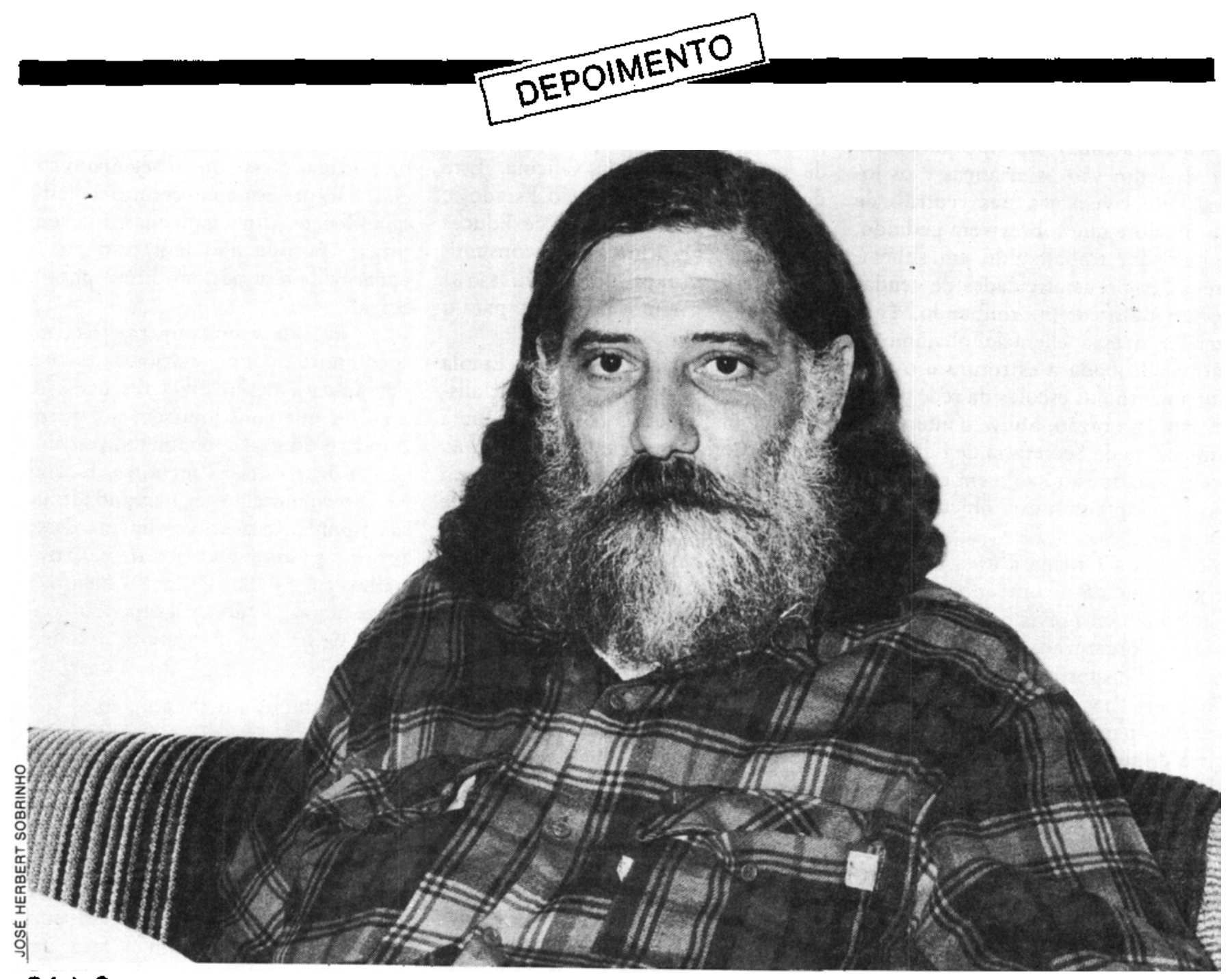

\title{
Odalr Sass
}

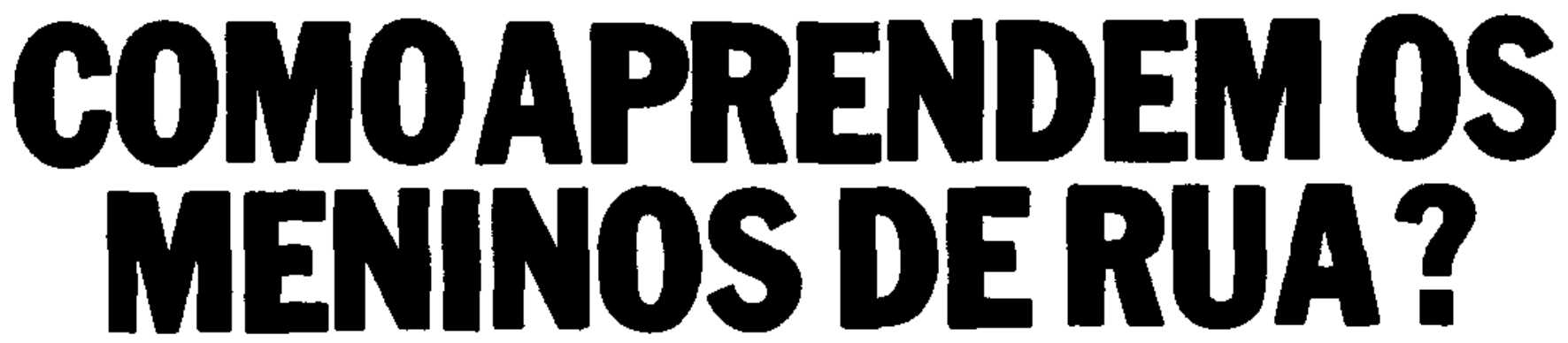

A Escola Oficina está desenvolvendo a proposta de tornar a educação e o trabalho acessíveis aos meninos de rua, a fim de garantir os seus direitos enquanto menores de idade $e$ possibilitar as condiçōes para o exercício pleno da sua cidadania. Foi o que nos relatou o colega Odair Sass, um dos fundadores da Escola Oficina, criada em 1985 e instalada nas imediações da Praça da Sé, em São Paulo. Em seu depoimento, Odair avalia o trabalho da Escola Oficina como uma tentativa de avançar no propósito de atender às necessidades da população de menores de rua numa perspectiva educacional, ao invés de entender que os problemas vividos por eles são caso de polícia ou de promoção social. 
Desde o início, a Escola Oficina se propôs a atender um tipo particular de alunado: são as crianças e os jovens que vivem nas ruas centrais de São Paulo e que sobrevivem pedindo, esmolando, trabalhando $\mathrm{em}$ subempregos como as atividades de vendas nos semáforos, ou roubando. Para atender a essa clientela obviamente não é adequada a estrutura $e$ o funcionamento das escolas da rede pública. Por essa razão, houve o interesse e a iniciativa da Secretaria de Educação do Estado de São Paulo em criar uma escola adaptada a este objetivo específico.

A Escola Oficina é uma escola de $1^{\circ}$ grau que dá o conteúdo curricular conforme está previsto na lei. No entanto, a organização desse conteúdo não está disposto em oito séries seqüenciais, mas pode ser aprendida de maneira não-seriada ou desseriada. Além disso, o aluno pode fazer a matrícula em qualquer período do ano e a escola se propõe a montar a sua grade curricular de maneira que seja flexível ao aluno em termos de horário e de unidade de conhecimento.

\section{Oficinas de alfabetização e de marcenaria}

Por que a Escola Oficina tem esse nome? Procuramos recuperar o significado inicial de oficina que é um processo de construção tanto de um objeto quanto de um conhecimento. Assim, as nossas salas de aula são denominadas de oficinas: temos oficinas de matemática ou de alfabetização, como temos oficinas de marcenaria ou de eletricidade. Mais do que locais, as oficinas são atividades nas quais o processo é o conjunto de construçâo de conhecimento - seja o ato de escrever ou de produzir um objeto qualquer. Os professores e os alunos não são depositários e depositantes de um conhecimento acabado, mas são atores de um processo de construção permanente.

O trabalho na Escola Oficina tem a seguinte operacionalização: a condição das crianças e dos jovens na rua impõe a necessidade de sobrevivência. Por isso, desenvolvemos as oficinas que permitem ao aluno aprender determinados conteúdos técnicos mínimos e produzir os objetos de uso que possam ser comercializados. Este objetivo está contido no próprio decreto de criação da Escola Oficina. Este decreto ainda prevê que o Estado, e em particular a Secretaria de Educação, deve ser o primeiro dos consumidores do que for produzido ali. Isso se reverterá em termos de salário para o aluno.

O objetivo da proposta da Escola Oficina não é o de formar especialistas em marcenaria, pois não é uma escola profissionalizante. E claro que, para produzir uma carteira ou um cesto de lixo, deve-se ter o domínio de determinados conteúdos técnicos de marcenaria. Além disso, pretendemos que a situação de aprendizagem permita aos alunos duas coisas fundamentais: garantir a sua sobrevivência e adquirir uma preparação para o trabalho ao desenvolver uma concepção do que sejam as relaçōes de trabalho na nossa sociedade.

\section{A atuação da equipe de saúde mental}

Num primeiro momento, fizemos uma divisão de trabalho e um pessoal da escola ficou ligado à área de saúde. O psiquiatra e o psicólogo propuseram um plano de trabalho em termos de saúde física e mental. Nesse aspecto da saúde mental, percebemos alguns problemas'e dificuldades que exigiam uma atuação com os funcionários da escola desde os professores até a equipe operacional e a técnica. Apesar de toda a disponibilidade das pessoas que trabalham ali, não havia uma clareza maior sobre o que é uma criança, o que é um jovem e quais são as dificuldades deles. Só para dar um exemplo, escreve-se e diz-se freqüentemente que $o$ adolescente $\dot{c}$ muito agressivo, muito rebelde. Esses menores de rua também são agressivos e rebeldes. Só que a rebeldia e a agressividade deles nos parece como coisa de marginal e nos esquecemos que são características comuns a todos os adolescentes. A resolução da situação de agressividade é distinta nas diferentes classes sociais. No nosso segmento de classe média, quando havia uma situaçäo de briga na rua, a gente chegava naquele ponto em que aparecia um terceiro, colocava a mão entre os dois moleques e dizia: "quem for homem, cospe aqui primeiro". Esse terceiro queria ver se desencadeava uma briga. Nesse outro segmento social, não precisa aparecer um terceiro quandos os dois moleques querem brigar, porque não têm restrição à agressividade e partem direto para a briga.

Através de grupos operativos com o conjunto de funcionários da escola, passamos a desenvolver discussões e análises que contribuíssem no entendimento do desenvolvimento psicológico e físico desses menores. E também reconhecemos a necessidade de acompanhar o desenvolvimento desse próprio grupo de funcionários. O trabalho na Escola Oficina é tenso e exige uma coesão de grupo do conjunto de funcionários muito grande.

\section{E os alunos que cheiram cola?}

Qual é a atuação do psicólogo ou de outro profissional na Escola Oficina? Eu me lembro que, na primeira semana, houve uma briga de faca dentro da escola. Um menino deu uma facada no outro; o psicólogo e o pedagogo da escola voaram em cima desse menino e tiraram a faca das suas mãos. Esse era o nível de atuaçāo exigido.

Um outro nível de atuaçào ć que essa ênfase no acompanhamento do próprio conjunto de funcionários da escola revelou-se importante e produtivo. Devido a atuação da equipe de t rabalho foram eliminadas certas condutas que, quando encaradas somente no plano individual, seriam de solução muito mais complicada.

Por exemplo, qual ć o tipo de abordagem que nós desenvolvemos no caso de os alunos cheirarem cola de sapateiro na escola? Existem algumas regras a esse respeito na escola: não pode entrar com tóxico, não pode entrar com arma, não pode entrar com produto de roubos e tem de respeitar os horários e a dinâmica de funcionamento da escola. Com relação à cola de sapateiro, algumas crianças conseguem escondê-la no meio das pernas ou debaixo da camisa. Quando descobrimos e tomamos a cola, isso geralmente desencadeia uma crise muito agressiva do menino. O que a gente faz? Contém a crise. 


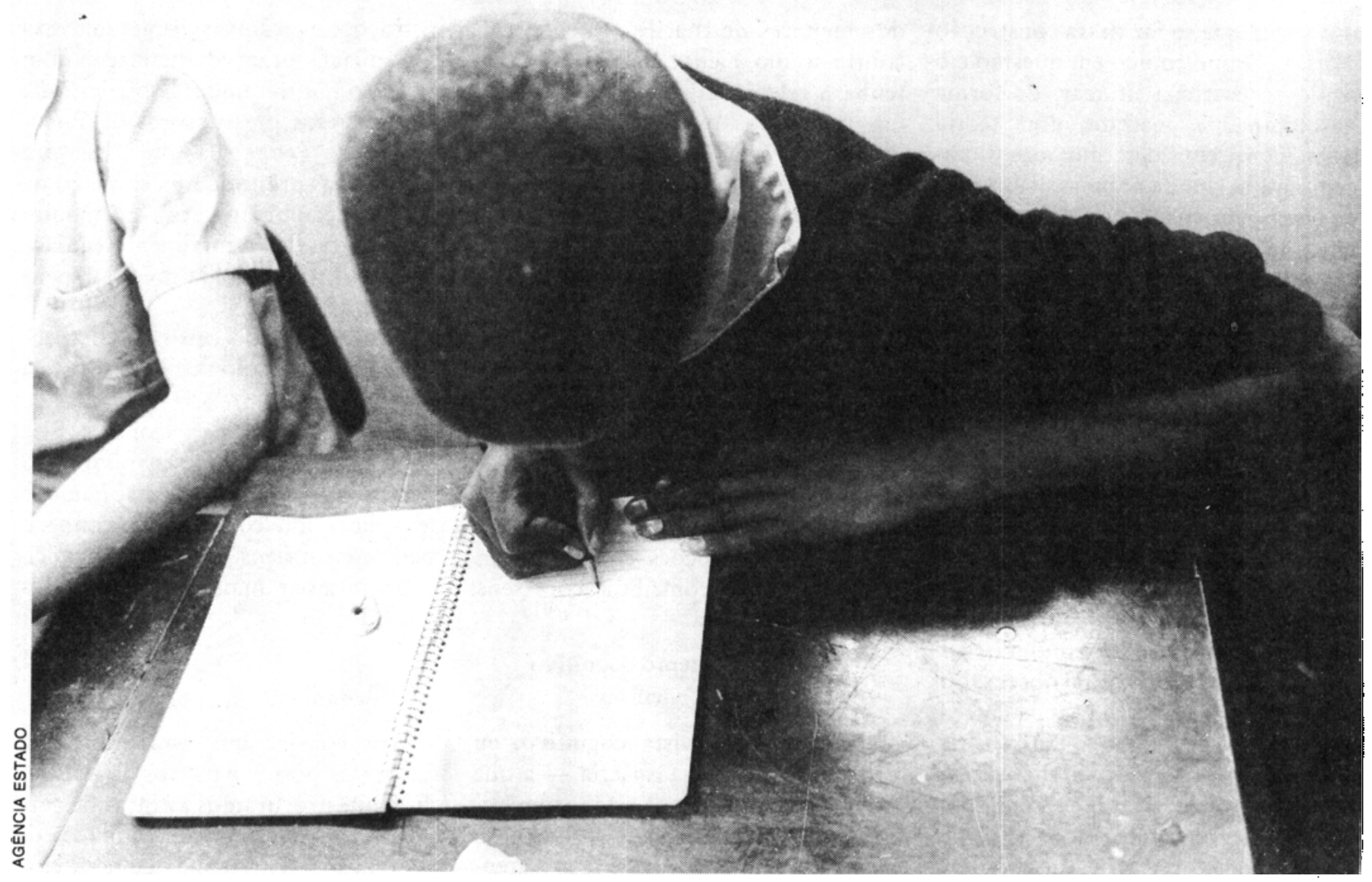

Durante quinze, vinte minutos o menino fica se debatendo, agredindo. Superada essa fase muito forte, o menino entra em"stress"depois acaba se conduzindo a outras atividades da escola, na maioria das vezes, como se nada tivesse acontecido. Esse é o nível de atuação que desenvolvemos.

Uma série de casos evidencia que uma organização adequada de compreensão e de atendimento de uma equipe de trabalho cria condições quero lembrar que isso não ocorre de maneira automática - para superar, por exemplo, o uso de cola. Observam-se em vários alunos da Escola alguns deles conhecidos como grandes cheiradores de cola - mudanças até físicas e eles mesmos dizem:-" $\mathrm{Pa}$ rei de cheirar cola durante o dia, estou cheirando só à noite". A própria organização da escola, as atividades e as relaçöes estabelecidas lá fazem com que essas crianças e jovens acabem substituindo os tóxicos por essas outras atividades $e$ relações na escola. Pode-se concluir que as dificuldades individuais não devem ser tratadas somente do ponto de vista do Joãozi- nho, mas na disposição de condiçōes que permitam ao Joãozinho superar essa situaçāo vivida por ele.

\section{A teoria e seu uso social}

Uma vez recebemos a visita de um psiquiatra na escola, que ficou observando um dos meninos mais espertos. Esse psiquiatra verificou que, a cada dez minutos, o menino estava chorando nas mais diferentes situações. Ele tinha ido arrumar briga com um outro maior ou menor do que ele. Como tem um porte físico pequeno, vivia apanhando e chorando. $\mathrm{Na}$ base da brincadeira, o psiquiatra nos disse assim:- "Esse menino é um masoquista". Obviamente, o psiquiatra estava usando o termo mais como uma manifestação pessoal para entender o que estava acontecendo com o menino do que como um conceito nosográfico. Apesar de fazer esta ressalva, traduz de alguma maneira o que o psiquiatra pensa dessa situação.

Esse menino viveu um processo na escola em que, no prazo de um mês, foi alfabetizado, reencontrou o seu pai na estação de metrô da Praça da
Sé e mudou radicalmente as suas condutas e atitudes. Se tomarmos, hoje, esse menino sendo observado pelo mesmo psiqujatra, vamos concluir que o menino não é masoquista. $O$ exemplo é forçado, mas tem o objetivo de mostrar que 0 diagnóstico ou o conceito usados na Psiquiatria e na Psicologia devem ser examinados de maneira crítica.

O profissional lida cotidianamente com uma situação real e concreta, recorrendo a uma leitura teórica sem se dar conta, muitas vezes, da interferência dessa sua leitura no contato com a realidade concreta. Eu arriscaria dizer que determinados conceitos da Psicologia e da Psiquiatria não são conceitos intrínsecos a todos os indivíduos, como se costuma supor, mas são conceitos que também se referem a classes sociais. Obviamente o masoquismo está presente na burguesia, no proletariado ou em qualquer outra classe. A teoria psicológica ou psiquiátrica não tem um conteúdo de classe social pela sua construção teórica, mas tem pela sua interpretação concreta das relaçōes de vida, pelo 
uso social que se faz dessa construção teórica. O que coloco em questão é o como se costuma utilizar, de forma absolutamente abstrata, uma teoria para interpretar determinadas situações muito momentâneas, supondo que tem em mãos um instrumental único que permite ao profissional fazer um diagnóstico e prescrever um tratamento.

\section{Os estudos a serem desenvolvidos}

A Psicologia tem a desenvolver, em termos de compreensão e de práxis relacionados ao menor, dois grandes temas: o desenvolvimento afetivo e o cognitivo.

$\mathrm{Na}$ relação com esses meninos de rua, observamos que em determinadas situações eles têm condutas surpreendentes. Não é casual observar os meninos de sete ou oito anos enfrentando situações como se fossem um adulto. Por exemplo, a situação de sobrevivência, que implica o enfrentamento com os adultos, com a polícia, com o educador etc, em que têm uma referência de comportamento como se tivessem 17 ou 27 anos, ao invés de terem 7 ou 8 anos

No contato com os menores que têm 17 ou 18 anos, há condutas em determinadas situaçōes que traduzem uma carência afetiva absoluta. Eles tomam o outro, o educador por exemplo, como referência e se conduzem como se fossem crianças com 7 anos.

Em termos afetivo-emocionais, há um aspecto muito importante a ser estudado. Precisamos entender qual é a dinâmica de organização interna dos menores de rua. Raramente, encontra-se um menor de rua que näo tenha a referência de um líder ou de um grupo aos quais está vinculado devendo prestar determinados serviços e que, na contra-partida, recebe proteção do grupo.

Um item interessante dentro dessa dinâmica de rua é o uso de tóxicos, por exemplo. Na rua, existe uma hierarquia no uso de tóxicos. A cola é usada em geral pelosmeninosmenores. Os médios vão şe afastando da cola e vāo se adentrando no fumo (maconha). Os meninos maiores têm como referência o fumo e outras drogas mais "pesadas", como a cocaína. Isso resulta de percepções empiricas e a Psicologia deve contribuir com seus estudos nessa área.

\section{Odesenvolvimento cognitivo desses meninos}

Do ponto de vista cognitivo, eu diria que a extrema miséria - a que essas crianças e jovens estão submetidos - induz a um desenvolvimento muito sagaz, muito vivo e muito atento pois são obrigados a compreender determinadas situaçōes muito rapidamente. Se for estabelecida uma relação com essas crianças, temos no processo e no desenvolvimento escolar situações de aprendizagem muito mais rápida $e$ fácil do que em situações semelhantes de dificuldades observadas nas crianças ditas "normais". Estando eles mesmos convencidos de que "aqui é escola e eu quero estudar", num prazo curto de tempo apresentavam os resultados de aprendizagem. Por exemplo, passavam a primeira semana fazendo a cópia de

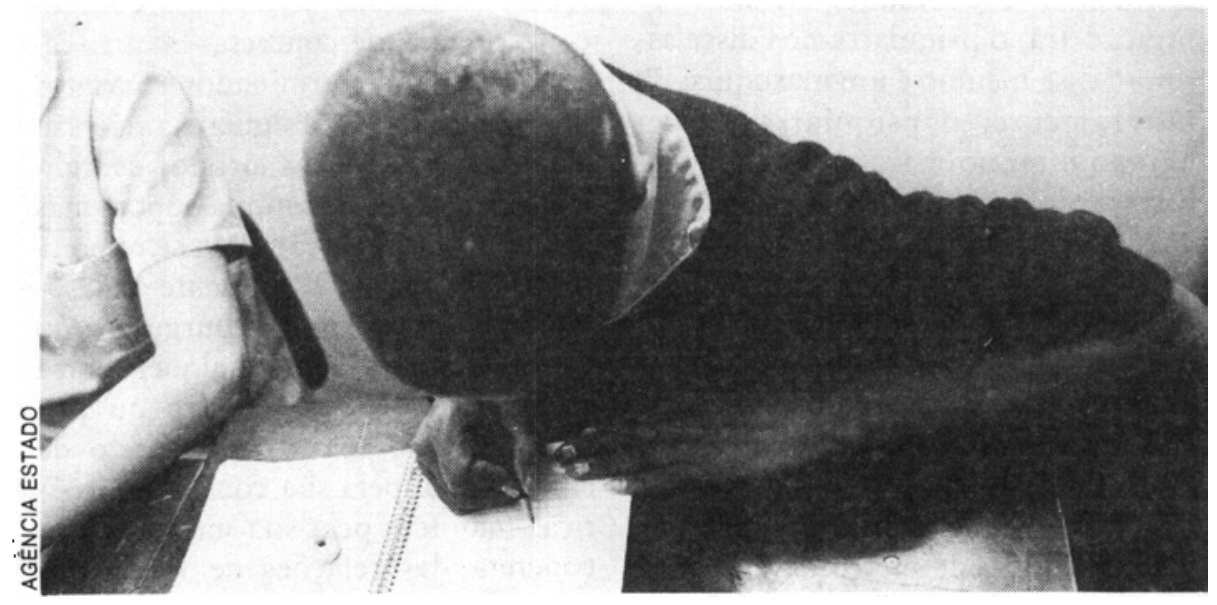

instruções mecânicas; superada essa fase inicial, foram alfabetizadas num processo muito rápido. Isso questiona determinados pressupostos da Psicologia e da Pedagogia que dissertam sobre certas prontidóes necessárias na alfabetização. Não estou afirmando que essa tese está totalmente equivocada, mas a Psicologia precisa repensar este aspecto.

Obviamente, há casos de comprometimento neurológico e outros de dificuldades de aprendizagem, mas de maneira geral isso não acontece. Eles têm a capacidade de desenvolvimento cognitivo e são capazes de aprender e de aplicar um conjunto de conhecimentos científicos. A Psicologia precisa aprofundar mais os seus estudos nesta direção.

\section{A cidadania dos menores de rua}

Aos colegas que estão nos mais diferentes postos e pontos do país, eu diria que p ocuramos avançar no propósito de atender às necessidades da população, ao trabalhar com os chamados menores de rua numa perspectiva educacional. Precisamos entender que os problemas vividos pelos segmentos desfavorecidos da população não são casos de polícia e nem de promoçāo social. Lidar com estes problemas através da educaçāo é um princípio geral importante.

Dentro deste princípio, o núcleo essencial da proposta educacional da Escola Oficina é a relação entre educação e trabalho. Para nós, é fundamental a criança e o jovem terem acesso a uma escolarizaçāo crítica. Não se trata de dar um pouco de aulinha para essas crianças, mas de organizar e de possibilitar uma escolarização crítica que propicie a compreensão de sua condição de vida. Assim, elas vāo ter acesso a instrumentais e conhecimentos a que todos os cidadãos têm direito.

A preparação para o trabalho entra como um elemento importante no conjunto da proposta educacional da Escola Oficina. Esse processo educacional deve garantir às crianças os seus direitos enquanto criança e que também tenham o preparo para o exercício pleno da cidadania. 